\title{
Effect of Nursing Interventions on Self-management Behaviors of female Geriatric patients with Liver Cirrhosis
}

\author{
Naglaa Alsaied Mostafa Alfauomy, Assistant Lecturer \\ Gerontological Nursing, Faculty of Nursing, Damanhour University \\ Somaya Abdel Moneim Elshazly, Professor \\ Gerontological Nursing, Faculty of Nursing, Alexandria University \\ Abeer Abd El Galeel Abd EL Moneam, Assistant Professor
Gerontological Nursing, Faculty of Nursing, Alexandria University
}

\begin{abstract}
Liver cirrhosis $(L C)$ is a serious, irreversible and silent disease prevalent among geriatric patients that results in development of complications leads to high morbidity, frequent hospital admissions and mortality. In this context, the role of nurses in the care of geriatric patients with liver cirrhosis should focus on improving self-management behaviors which in turn would lead to minimize the progression of the disease, prevent complications, facilitate their optimal functional ability and enhance their quality of life. Objective: Determine the effect of nursing interventions on selfmanagement behaviors of female geriatric patients with liver cirrhosis. Setting: The hepatology ward of the medical department of Damanhour National Medical Institute, El-Behaira Governorate, Egypt. Subjects: The study subjects included 50 female geriatric patients with liver cirrhosis divided equally into two matched groups of 25 each. Tools: Four tools were used for data collection: I)The MiniMental State Examination (MMS), II) Socio-Demographic and Clinical Data of Female Geriatric Patients with Liver Cirrhosis Structured Interview Schedule, III) Female Geriatric Patients with Liver Cirrhosis Knowledge Assessment Structured Interview Schedule, and IV) Self-Management Behavior Scale for Liver Cirrhosis Patients. Results: A highly statistical significant Improvement in overall selfmanagement behaviors of female geriatric patients with liver cirrhosis was found in the study group post interventions $(p<0.0001)$ compared to pre interventions. A statistically significant difference was found between the study and control groups post interventions regarding dietary, medication and illness monitoring management. As well, significant Improvement was found in the study group knowledge level regarding liver cirrhosis post interventions. Conclusion: Nursing interventions had affected positively the level of knowledge and self-management behaviors of female geriatric patients with liver cirrhosis. Yet, occurrence of complications, readmission to hospital and death rate could not be affected significantly by nursing interventions in study group. The main factors affected significantly self-management behaviors of female geriatric patients were age, educational level and income. Recommendations: Coordination with different health care settings for application of this program for geriatric patients with compensated LC admitted to out-patient clinics for better results, prevention of complication, decreased hospitalizations and resource utilization.
\end{abstract}

Keywords: Nursing Interventions; Self-Management Behaviors; Liver Cirrhosis; Female Geriatric Patients.

\section{Introduction}

Liver cirrhosis (LC) is a serious and irreversible disease. It is the final stage of chronic liver disease characterized by replacement of liver tissue by fibrotic scar tissue and regenerative nodules, resulting in progressive loss of liver function ${ }^{(1)}$. LC is responsible for a number of complications, resulting in consecutive hospitalizations, increasing societal costs, impairment of quality of life and reduction in life expectancy $^{(2)}$.

LC is considered the second cause of death among gastrointestinal diseases. The exact prevalence of cirrhosis is unknown because the disease is often silent ${ }^{(3,4)}$. The prevalence of liver diseases increases with aging, and geriatric patients are more likely to develop advanced liver disease than 
younger patients. Moreover, half of geriatric patients who develop LC die within one year of diagnosis ${ }^{(5)}$. Mortality from LC in geriatric patients was 12 times higher than that in younger patients in $\operatorname{Iran}^{(6)}$. According to the latest WHO data published in 2017, liver disease deaths in Egypt constituted $10.45 \%$ of total deaths. The age adjusted death rate is 84.71 per 100,000 of population ranks Egypt number one in the world ${ }^{(7)}$. The number of deaths due to liver disease and cirrhosis in Egypt between the years 2008 and 2010 increased with age. It rose steadily until age 35-54; then increased rapidly until it reached a peak at age 55-74, and then it declined gradually ${ }^{(8)}$. About $37 \%$ of older adults attending the medical department of Damanhour National Medical Institute at ElBehaira Governorate during (2017) suffered from liver cirrhosis ${ }^{(9)}$.

Aging is associated with a variety of changes in liver morphology and function including decreased liver weight and liver blood flow due to reduced cardiac output, decreased number of hepatocytes, decreased metabolic function, and reduction of liver detoxification $^{(5,10)}$. The total volume of cytochrome p450 decreases to $70 \%$ of its original level in people over 70 years old, resulting in decreased liver metabolism and detoxification $^{(11)}$. These changes put the geriatric patients at risk for developing and accelerating liver diseases. Also, the clinical characteristics and management of liver diseases in geriatric patients are affected by these liver changes ${ }^{(5)}$.

There are many causes of liver cirrhosis among female geriatric patients. The most common causes are fat accumulating in the liver (nonalcoholic fatty liver disease (NAFLD)) and chronic viral hepatitis $(C)^{(10)}$. After 60 years of age, the prevalence of NAFLD is higher in women due to Insulin resistance, which is accompanied by abdominal obesity and excessive visceral fat. When women gain weight, fat accumulates in the liver cells. This creates a toxic environment for the liver, which leads to fibrosis, then cirrhosis and eventually cancer. Fatty liver is rapidly becoming the second reason for liver transplantation $^{(12,13)}$.

A study done in Egypt (2013) revealed that abdominal symptoms, fatigue, worry, decreased energy, and activity were major problems and symptoms of cirrhotic patients that impaired their quality of life ${ }^{(14)}$. Also, various complications of liver cirrhosis including ascites, hepatic encephalopathy, gastrointestinal tract bleeding from varices, and skin symptoms could be severer in geriatric patients and can further worsen the course of the disease ${ }^{(10)}$. This may result in reduced physical activity, restrictions in daily life and even a decrease in working hours and social activities ${ }^{(15-17)}$.

Literatures revealed that geriatric Patients with liver cirrhosis lack important knowledge about disease self-management. Lack of knowledge about the disease is considered barrier for attaining the therapeutic goals for these patients ${ }^{(18,19)}$. Self-management is a low-cost and effective method that could have a positive impact for patients' rehabilitation ${ }^{(14)}$. It is a dynamic, interactive, and daily process in which individuals engage actively in managing a chronic illness ${ }^{(20)}$. Self-management requires knowledge and skills about disease such as adherence to drug treatment, dietary intake, exercise regimens, and observation and management of symptoms ${ }^{(21)}$.

Improving self-management behavior of geriatric patients with liver cirrhosis means increasing patients' knowledge by describing the facts about the disease and its management that patients need to understand to enable them to perform complex self-care activities $^{(20)}$. A variety of studies revealed that active participation of geriatric patients with liver cirrhosis in caring for themselves, increase their responsibility for controlling the symptoms and complications, shorten recovery, and decrease hospital stay, resource utilization and re-hospitalization rate $^{(19,22)}$. 
Nurses in their day to day contact with geriatric patients have the best opportunity to assess their potential problems, discuss medical regimens and give teaching about all aspects of care. They also have an important role in helping patients to maintain physical activity safely, recognize activity limitations and conserve energy. Moreover nurse can also teach patients necessary modifications, adherence to medication schedule and maintenance of life style changes that best suit them ${ }^{(23,24)}$.

\section{Aim of the Study}

This study aims to determine the effect of nursing interventions on self-management behaviors of female geriatric patients with liver cirrhosis.

\section{Research Hypothesis}

Female geriatric patients with liver cirrhosis who receive the proposed nursing interventions exhibit higher selfmanagement behaviors than those who do not receive the proposed interventions.

\section{Materials and Method}

\section{Materials}

Design: A quasi-experimental research design was used to carry out this study.

Setting: The study was carried out at the hepatology ward of the medical department of Damanhour National Medical Institute, El-Behaira Governorate, Egypt. The hepatology ward consists of six rooms; three for females and three for males with a total capacity of 38 beds. This ward has admission rate of about 125 female geriatric patients with liver cirrhosis every three months. The average duration of hospital stay ranges from one to two weeks.

Subjects: The study subjects comprised fifty (50) female geriatric patients with liver cirrhosis admitted to the above mentioned setting during the period of the data collection; and fulfilling the following criteria; age 60 years and above, able to communicate effectively, diagnosed with liver cirrhosis for at least 6 months, planned for discharge within two weeks and with normal cognitive functions or mild cognitive impairment. They were divided equally into two matched groups; of 25 female geriatric patients with liver cirrhosis.

Group 1: Control group received the routine hospital care.

Group 2: Study group received the proposed nursing interventions.

The sample size was estimated based on Epi info V 7.0 program using the following parameters: Population size: 125, Expected frequency: 50\%, Acceptable error: 10\%, Confidence coefficient: $95 \%$. The program revealed a minimum sample size of 42 geriatric women with liver cirrhosis. However, this study was conducted on a sample size 50 female geriatric patients for the purpose of improving validity of the research results.

Tools: In order to collect the necessary data, four tools were used:

\section{Tool I: Mini Mental Scale Examination (MMSE)}

The Arabic version of the MMSE translated and adapted by ELOKL $(2002)^{(25)}$ was used in the study. It is a reliable measure for assessing the cognitive function of the elderly (reliability coefficient of 0.93 and 0.91 for normal and demented elderly persons respectively). It consists of 10 items that investigate memory, orientation to time and place, attention, calculation, naming, repetition, registration, language, praxis and coping of a design. The maximum score is 30. Elders scoring from 24 to 30 were considered to have no cognitive impairment and those from 18 to 23 were considered to have mild cognitive impairment.

Tool II: Socio-Demographic and Clinical Data of Female Geriatric Patients with Liver Cirrhosis Structured Interview $\underline{\text { Schedule }}$

This tool was developed by the researcher based on review of relevant literatures; to collect the required data from the study subjects. It consisted of two parts; 
Part (1): Socio demographic data such as age, level of education, marital status, residence and monthly income.

Part(2): Clinical data was obtained from medical records such as the date of admission to the hospital, duration of illness, causes of liver cirrhosis, complications, previous hospitalization within last year, presence of comorbid diagnosed medical diseases and medications used.

\section{Tool III: Female Geriatric Patients with}

Liver Cirrhosis Knowledge Assessment Structured Interview Schedule

This tool was developed by the researcher to evaluate the knowledge of the female geriatric patient with liver cirrhosis such as definition of LC, causes, clinical manifestations, treatment and complications. In order to calculate the total score of this tool; each correct answer scored one while wrong answer or don't know scored zero. The female geriatric patients who had knowledge percent score $<50 \%$ were categorized as having unsatisfactory knowledge level, while those who had percent score $\geq 50 \%$ were categorized as having satisfactory knowledge level.

Tool IV: Self-Management Behavior Scale for Liver Cirrhosis Patients

It was developed by Wang et al. $(2015)^{(26)}$ and used to assess selfmanagement behaviors of patients with liver cirrhosis. It consists of 24 items and has 4 dimensions: dietary management (7 items), daily life management ( 7 items), medication management (5 items), and illnessmonitoring management (5 items). A 4points Likert-type scale was used to report self-management behaviors: all the time (4), most of the time (3), sometimes (2), rarely (1). The score for overall self-management behaviors was obtained by calculating a mean of the individual's response to all 24 items; the four subscales scores were obtained by calculating the mean of the responses in each subscale items ${ }^{(20)}$.

\section{Method}

- Official permission to carry out the study from the responsible authorities from the Faculty of Nursing, Alexandria University was obtained and forwarded to the head of the study setting of Damanhour National Medical Institute at El-Behaira Governorate to obtain his assistance and approval to carry out the study.

- Permission from the head of the study setting was obtained after being informed about the purpose of the study, the date and the time of data collection and after providing a copy of the study protocol and the study booklet.

- The Arabic version of tool I was used to assess the female geriatric patients in order to identify those who had normal cognitive function or mild cognitive impairment to be included in the study subjects.

- Tools II and III were developed by the researcher based on a thorough review of relevant literatures.

- Tool IV was translated into Arabic language by the researcher.

- Tool III and IV were tested for content validity by five experts in the related fields of Gerontological Nursing and Medical Surgical Nursing. Reliability of Tool III and tool IV were tested using Cronbach's alpha. The reliability results for tool III was $r=0.90$, and tool IV was $\mathrm{r}=0.68$.

- A pilot study was carried out on 5 female geriatric patients with liver cirrhosis to assess the applicability, clarity and feasibility of the study tools; they were selected from the study setting and excluded from the study subjects. The necessary modifications were made in areas of diet and sleeping to be in accordance of our culture and age related changes. 
- The nursing interventions were developed by the researcher based on through review of the relevant literatures on the needed knowledge and skills required for selfmanagement behavior for female geriatric patients with liver cirrhosis. It included needed knowledge related to the importance of the proposed nursing interventions sessions, planned goals to be achieved from the participation in the study, simple and basic information about liver cirrhosis, meaning and benefit of selfmanagement behaviors, healthy diet, fluid intake, daily life (hygiene, measures to relieve health problems and rest and sleep), medications, follow up and how to manage complications. The nursing intervention were prepared and divided into six sessions.

- The researcher visited the hospital daily to identify subjects who fulfill the inclusion criteria. Each study subjects was interviewed individually to include those who had normal cognitive functions or mild cognitive impairment using the Mini-Mental State Examination (MMSE) scale.

- In order to prevent contamination between participants of study and control groups, all female geriatric patients with liver cirrhosis admitted to the hospital during the data collection period and fulfilling the inclusion criteria were assigned to the control group until reaching the required number (25 subjects). Then the following admitted 25 geriatric patients were assigned to the study group.

- Before starting the program, participants from both study and control groups were interviewed individually in order to assess their baseline data such as (sociodemographic data, knowledge and self-management behaviors) using tool II, III and IV. The researcher conducted the assessment in the ward within 24 hours after patient's admission.

- Two weeks before discharge, each female geriatric patient attended the nursing interventions sessions individually in the hepatology ward of medical department of the study setting. The proposed nursing interventions were implemented in 6 sessions over two weeks period (3 sessions per week). The duration of each session ranged from 30-45 minutes. Sessions 2 to 6 started with the objectives of the session followed by a summary of the previous session then the needed interventions.

- Session I (significance and content of the program); the researcher was started by explaining the importance of the proposed nursing interventions sessions, planned goals to be achieved from the participation in the study and outlines of session's content. Thereafter, the researcher clarified simple information about liver functions and age related changes affecting liver.

- Session II (basic information about liver cirrhosis) was included teaching the female geriatric patient about meaning of liver cirrhosis, its causes, signs and symptoms, treatment and complications. In addition to meaning and benefit of selfmanagement behaviors.

- Session III (therapeutic diet for liver cirrhosis) included teaching the female geriatric patient about importance of healthy diet, low salt diet, high protein diet, low fat diet, tea and caffeine consumption, fluid intake and give examples of 
healthy diet according to the patient condition and economic status.

- Session IV (daily life style) included teaching the female geriatric patient about oral hygiene and skin care for pruritis, how to deal with liver cirrhosis symptoms as edema, anorexia, pruritus, dry mouth, difficult breathing and rest and sleep were performed.

- Session V (liver cirrhosis medication) included teaching the female geriatric patient about importance of medications, types of medication used for patients with liver cirrhosis and instruction for using it. It also included contraindicated medications and how to comply with medications and needed immunization for patient with liver cirrhosis.

- Session VI (follow-up) included teaching the female geriatric patient about follow up for illness monitoring such as needed ultrasound of liver and blood test every 6 months and how to manage complications (such as ascites, haematemsis, melena, jaundice and hepatic encephalopathy).

- Before each session the researcher measured the patients' weight and abdominal girth in order to motivate patient to continue participation in the study and teach him how to monitor ascites.

- During each session, flip chart with illustrative pictures and the main points of content in a simple way was used to clarify the desired knowledge and skills for each patient. In addition to open discussion, videos and demonstration were used as teaching methods.

- In each session, the researcher summarized the main points in the session and allowed time for asking questions and answers. Motivation for patients was provided to ensure active participation through asking the geriatric patients questions about the content of sessions and giving them simple prizes such as tooth brush, soap and toilet papers.

- The researcher provided the female geriatric patients and their caregivers with booklet illustrating the activities and goals of the proposed nursing interventions to guide and enrich their memory about the activities in each session. The booklet was written in Arabic language, and entailed mostly pictures for more clarity.

- The telephone number and address of each study participant was taken to check their consistency with the proposed nursing interventions and arrange for upcoming meetings.

- The researcher conducted sessions from 8 am to 2 pm with 5 sessions per day.

- The data collection started from the mid-August 2019 until mid-January 2020.

- Sessions were provided for3different patients every week of data collection.

- After one month from their discharge from hospital, the researcher met each patient at the out-patient clinic to evaluate the effect of the program by using the tools; III and IV. Also, the evaluation included indicators related to number of readmissions to the hospital, occurrence of complications, and number of death during this period. 


\section{Ethical considerations:}

An informed consent was obtained from each study subject included in this study after explanation of the study purpose. Anonymity and privacy of the study subjects, confidentiality of the collected data and the subject's right to withdraw at any time will be maintained.

\section{Statistical Analysis}

Data were fed to the computer and analyzed using IBMSPSS software package version 20.0. Comparisons between groups for categorical variables were assessed using Chi-square test (Fisher or Monte Carlo). Student t-test was used to compare two groups for normally distributed quantitative variables. McNemar Test and Paired t-test were used for comparison between two periods for normally distributed quantitative variables. Significance of the obtained results was judged at the $5 \%$ level.

\section{Results}

Table (1) shows the distribution of the study and control groups according to their socio-demographic characteristics. The age of the study and control groups ranged from 60 up to 86 years with a mean of $66.84 \pm 4.26$ years for those in the study group compared to $66.1 \pm 6.3$ years for the control group. More than half of the study and control groups $(56 \%$ and $52 \%)$ respectively were married. No statistical significant difference was noticed between the study and control groups regarding the age and marital status $(\mathrm{p}=0.639, \mathrm{p}=1.000$, respectively)

In relation to level of education, the table shows that $56 \%$ and $64 \%$ of the study and control groups respectively were illiterate. $72 \%$ of the study group and $56 \%$ of the control group lived in rural areas. Regarding living arrangement, $96 \%$ and $84 \%$ of both the study and control groups were living with family or relatives. No statistical significant difference was noticed between the study and control groups regarding the level of education, residence, and living arrangement $(\mathrm{p}=0.081, \mathrm{p}=0.671, \mathrm{p}=0.695$ respectively)

According to their economic status, $60 \%$ of the study group and $52 \%$ of the control group reported no enough income. Pension was the main source of income reported by both the study and control groups $64 \%$ and $52 \%$ respectively. No statistical significant difference was noticed between the study and control groups $(\mathrm{p}=0.776,0.391$ respectively).

Table (2) shows the distribution of the study and control groups according to history of liver cirrhosis and reasons of current hospital admission. Regarding family history of liver cirrhosis, it was observed that $80 \%$ of the study group and $72 \%$ of the control group had no family history of liver cirrhosis. No statistical significant difference was noticed between the study and control groups $\mathrm{p}=1.000$.

Concerning duration of liver cirrhosis, it was ranging from one year to 14 years with a mean duration of $5.84 \pm 3.37$ and $6.1 \pm 3.3$ for the study and control groups respectively. It appears from the table that $56 \%$ and $40 \%$ of the study and control groups suffered from liver cirrhosis since one year to less than 5 years. No statistical significant difference was found between the study and control groups $p=0.597$. As regard the cause of liver cirrhosis, it is observed from the table that hepatitis $\mathrm{C}$ virus was prevalent among $64 \%$ and $72 \%$ respectively of both the study and control groups followed by Bilharasis constituted $20 \%$ and $16 \%$ of both the study and control groups respectively. No statistical significant difference was noticed between the study and control groups $\mathrm{p}=0.907$.

In relation to hospital admission in the last year, the same table shows that $60 \%$ of the study group reported that they were hospitalized during the last year either once $40 \%$, twice $33.3 \%$ or three times or more $26.7 \%$. As regard the control group $64 \%$ reported that they were hospitalized during the last year either once $31.25 \%$, twice 
$43.75 \%$ or three times or more $25 \%$. No statistical significant differences were noticed between the study and control groups regarding hospital admission and number of hospitalization in the last year respectively $\mathrm{p}=0.771$ and $\mathrm{p}=0.903$. Among the main reasons for the current hospital admission reported by both the study and control groups were ascites and difficult breathing were reported by $40 \%$ and $32 \%$ followed by haematemsis or melena constituted $32 \%$ and $40 \%$ respectively. No statistical significant difference was found between the study and control groups $\mathrm{p}=0.754$.

Table (3) shows the distribution of the study and control groups according to their level of knowledge regarding liver cirrhosis pre and post interventions. Satisfactory knowledge level regarding liver cirrhosis was reported by $12 \%$ of the study group pre interventions and this percent increased to $64 \%$ post interventions with a statistical significant difference between pre and post interventions in the study group $\mathrm{p}=0.001$. Also, a statistical significant difference was noticed between the study and control groups post interventions $\mathrm{p}=0.011$.

Table (4) shows comparison of prel post interventions mean score of selfmanagement behaviors in the study and control groups. Concerning overall selfmanagement behaviors, the mean score for the study group was $38.40 \pm 5.17$ pre interventions increased to $56.40 \pm 11.17$ post interventions with a statistical significant difference between pre and post interventions in the study group $\mathrm{p}=0.001$, While the mean score of overall selfmanagement behaviors for the control group was $41.08 \pm 6.08$ pre interventions compared to $43.80 \pm 7.63$ post interventions with no statistical significant difference between pre and post interventions in the control group $\mathrm{p}=0.179$. A statistical significant difference was found between both the study and control groups post interventions $\mathrm{p}=0.001$.

Regarding dietary management, the mean score for the study group was
$11.60 \pm 2.94$ pre interventions increased to $17.40 \pm 3.87$ post interventions with a statistical significant difference between pre and post interventions in the study group $\mathrm{p}=0.001$, While the mean score of dietary management for the control group was $11.72 \pm 2.46$ pre interventions compared to $12.68 \pm 2.70$ post interventions with no statistical significant difference between pre and post interventions in the control group $\mathrm{p}=0.272$. A statistical significant difference was found between both the study and control groups post interventions $\mathrm{p}=0.001$.

Concerning daily life management, the mean score for the study group was $11.80 \pm 1.73$ pre interventions increased to $16.04 \pm 3.18$ post interventions with a statistical significant difference between pre and post interventions in the study group $\mathrm{p}=0.001$, While the mean score of daily life management for the control group was $13.32 \pm 3.56$ pre interventions compared to 14. $24 \pm 3.59$ post interventions with no statistical significant difference between pre and post interventions in the control group $\mathrm{p}=0.398$. No statistical significant difference was found between both the study and control groups post interventions $\mathrm{p}=0.067$.

With respect to medication management, the mean score for the study group was $8.76 \pm 1.76$ pre interventions and increased to $11.76 \pm 2.35$ post interventions with a statistical significant difference between pre and post interventions in the study group $\mathrm{p}=0.001$, While the mean score of medication management for the control group was $8.72 \pm 2.37$ pre interventions compared to $9.08 \pm 2.47$ post interventions with no statistical significant difference between pre and post interventions in the control group $\mathrm{p}=0.577$. A statistical significant difference was found between both the study and control groups post interventions $\mathrm{p}=0.001$.

In relation to illness- monitoring management, the mean score for the study group was $6.24 \pm 1.48$ pre interventions increased to $10.80 \pm 3.23$ post interventions with a statistical significant difference 
between pre and post interventions in the study group $\mathrm{p}=0.001$, While the mean score of illness- monitoring management for the control group was $7.32 \pm 1.57$ pre interventions compared to $7.80 \pm 1.76$ post interventions with no statistical significant difference between pre and post interventions in the control group $\mathrm{p}=0.334$. A statistical significant difference was found between both the study and control groups post interventions $\mathrm{p}=0.001$.

Table (5) reveals the distribution of the study and control groups according to their hospital readmissions, occurrence of complications and number of death post interventions. Regarding hospital readmissions, $96 \%$ of the study group compared to $84 \%$ of those in the control group did not expose to hospital readmission post interventions with no statistical significant difference between both groups $\mathrm{p}=0.349$.

Concerning occurrence of new complication post interventions, $8 \%$ of study group compared to $20 \%$ of control group suffered from new complication with no statistical significant difference between the both groups $p=0.965$. As regard number of death post interventions, it was observed that $100 \%$ of both groups did not die with no statistical significant difference between the both groups.

In the present study, the main factors affected significantly self-management behaviors of female geriatric patients were age, educational level and income.

\section{Discussion}

Liver cirrhosis is a complex disease that may result in disturbances of different other organs including kidneys, heart, arterial circulation, lungs, gastrointestinal tract, and brain. Accordingly, geriatric patients with this disease develop a number of complications that lead to high morbidity, frequent hospital admissions and mortality $^{(27)}$. In this context, the role of nurses in the care of geriatric patients with liver cirrhosis should focus on improving self-management behaviors which in turn would lead to minimize the progression of the disease, prevent complications, facilitate their optimal functional ability and enhance their quality of life. These can be achieved through nursing interventions including information about measures of promoting rest, improving nutritional status, providing skin care, reducing risk of injury, and monitoring and managing complications ${ }^{(28,29)}$. Thus, the aim of this study was to determine the effect of nursing interventions on self-management behaviors of female geriatric patients with liver cirrhosis.

In the present study, results revealed that the implementation of nursing interventions had significant improvement post interventions with respect to selfmanagement behaviors of the studied female geriatric patients. The nursing interventions improved mean scores of overall selfmanagement behaviors of the study group (table 3). This finding may be interpreted as increasing the studied female geriatric patients' knowledge about their condition and its management enables them to perform complex self-management activities.

Also, the majority of the studied female geriatric patients were living with their family and relatives who provide support and help them in caring for themselves (table 1). Moreover, the researcher maintained continuous motivation, contact and guidance for them during implementation of the nursing interventions which could have helped in obtaining such results. Results of the present study are in agreement with those of other studies done in South Korea by Bae and Suh $(2001)^{(30)}$, in USA by Volk et al. $(2013)^{(19)} \&$ in United Kingdom by Beg et al. (2016) $)^{(31)}$ who reported that self-management behaviors of patient with liver cirrhosis improved significantly with simple educational interventions compared to the beginning of study. The findings of the present study are also supported by other studies done in Egypt by Mohamed and Mostafa $(2018)^{(32)}$ 
\& in USA by Ko et al. (2019) $)^{(33)}$ who demonstrated that patients with chronic liver failure who undergoing liver transplantation significantly engaging in various selfmanagement behaviors after nursing interventions.

In relation to dimensions of selfmanagement behaviors (dietary management, daily life management, medication management and illness monitoring management), the results revealed significant improvement in dietary management occurred post nursing interventions in comparison to the beginning of study (table 4). This can be justified by the finding that the majority of the studied female geriatric patients had unsatisfactory knowledge level before applying the nursing interventions (table 3). Also, compliance with therapeutic diet needs knowledge about different elements of food, how to deal with food problems related to disease as anorexia. Moreover, LC patients often have poor appetite, and salty foods are more appealing to them than the low-salt foods. Also, these problems were handled during the program such as teaching the studied female geriatric patients to use salt substitutes as vinegar and lemon juice and considering age related changes by consuming easily digested, prepared and low price diet. The findings of the present study are in accordance with other studies done in China by Ban et al. $(2017)^{(34)}$ \& Dong et al. $(2018)^{(20)}$ who found that nutritional dysfunction exists in patients with LC. Other studies who also reported a significant difference between the study and control groups before and after implementation of health education regarding nutrition were found in the literatures ${ }^{(28-30)}$.

Regarding daily life management (such as personnel hygiene, mouth and skin care, rest and sleeping, socialization and house keeping), after implementing the nursing interventions, a significant improvement in daily life management was found in the present study group (table 4). This result is supported by other studies done in South
Korea by Bae and Suh $(2001)^{(30)} \&$ in China by Zhang et al. (2019) ${ }^{(29)}$ who reported that using patient health education significantly increased sense of control over their life and their disease. This can be interpreted as all of the present study subjects were female who have the main role for them are caregiver who enable them to care for themselves. As well, they have better hygiene, care about their appearance, tend to have multiple social relations and contact and more capable of doing life management. In addition to Islamic religion teaches people part of daily life as personal hygiene, mouth care and rest and sleeping.

The present study also revealed a statistical significant difference between the study and control groups post interventions regarding medications management. Moreover, a significant difference between pre and post interventions among the study group was found (table 4). This is because medications can directly and clearly control the symptoms of liver cirrhosis which in turn encourage patients to adhere to medication schedule and better relief. Also, the program handled the problems facing the geriatric patients in comply with medications such as forgetfulness. Similarly, other studies done in South Korea by Bae and Suh $(2001)^{(30)}$, in USA by Volk et al. (2013) $)^{(19)}$, in Australia by Polis et al. (2016) ${ }^{(35)} \&$ in china by Dong et al. $(2018)^{(20)}$ demonstrated that patients with liver cirrhosis followed the medication schedule more strongly than the diet one.

Regarding illness-monitoring management, the present study found that the mean scores of illness- monitoring management of the study group were affected significantly by the implemented nursing interventions (table 4). Similarly, other studies done in different countries reported that a simple educational interventions significantly improved health maintenance and monitoring of patient with liver cirrhosis ${ }^{(19,29,30)}$. This may be due to follow up, and disease monitoring need knowledge about schedule of follow up (importance, time, place, type of medical 
checkup), available resources and services and complications which may occur in case of lack of follow up. Also, these elements were stressed in self-management interventions sessions.

In relation to the level of patients' knowledge about liver cirrhosis, before applying nursing interventions, the majority of patients in both the study and control groups had unsatisfactory knowledge. After applying nursing interventions, the majority of the study group had satisfactory knowledge compared to only few numbers of the control group. The difference was statistically significant between both groups and between pre and post interventions for the study group (table 3 ). An important point in this respect is the studied patients were illiterate explaining the obtained results related to unsatisfactory knowledge (table 1). Yet, most of the patients expressed a need of understanding and knowing more about liver cirrhosis, its complications, prognosis and management. Moreover, health-care staff in this study setting are busy and usually do not give them opportunity to ask questions.

The previous results are supported by other studies done in Iran by Mansouri et al. $(2017)^{(22)}$ and in Egypt by Elshamy $(2019)^{(36)}$ who demonstrated that there was a significant improvement in total knowledge scores of the intervention group one month after training on self-management skills. The present results are also in agreement with what was reported by Volk et al. $(2013)^{(19)}$ in USA, Beg et al. $(2016)^{(31)}$ in United Kingdom, Kadokawa et al. $(2017)^{(37)}$ in Japan, Goldsworthy et al. $(2017)^{(18)}$ in United Kingdom and Alavinejad et al. $(2019)^{(28)}$ in Iran. They all reported that patient's knowledge about liver cirrhosis was poor at the beginning of study and significantly improved after multimedia education.

As regard the hospital readmissions and occurrence of complications, these indicators were not affected significantly by nursing interventions (table 5). The present study results can be justified as these indicators need long period after applying the learned nursing interventions for improvement to appear. In this respect a study done in Australia by Wigg et al. $(2013)^{(38)}$ found nearly the same result of the current study and concluded that chronic disease management model for patients with chronic liver failure did not appear to reduce hospital admission rates. Conversely, other studies done in South Korea by Bae and Suh $(2001)^{(30)}$ and in Iran by Alavinejad et al. $(2019)^{(28)}$ found a significant difference before and after 6 months of interventions in occurrence of rehospitalization and complications.

In relation to the history of liver cirrhosis, more than half of the studied female geriatric patients suffering from liver cirrhosis since one to less than five years (table 2). This result can be justified by LC often is asymptomatic until the occurrence of decompensation and complication which lead to delayed discovery and diagnosis of disease. The present study is in agreement with other studies done in Iran by Zandi et al. $(2005)^{(39)}$, in Egypt, Assiut by Saleh et al. $(2014)^{(40)}$ and in China by Dong et al. $(2018)^{(20)}$ who reported more than half of the patients suffering from liver cirrhosis since1 to 3 years. Other studies done in Egypt, Fayoum by Mohamed and Mostafa $(2018)^{(32)}$ and in Egypt, Mansoura by Elshamy et al. (2019) ${ }^{(36)}$ contradict the result of the present study where it was observed that more than two fifths of patients with liver cirrhosis having the disease from 6-10 years.

Also, the main cause of liver cirrhosis for both the study and control groups was hepatitis $C$ virus (table 2). On the same line with the present study researches done in Egypt, Fayoum by Mohamed and Mostafa $(2018)^{(32)}$ and in China by Dong et al. $(2018)^{(20)}$ stated that about two thirds of the patients reported that the main cause of liver cirrhosis was HCV and HBV. Contrary several studies done in Australia by Wigg et al. $(2013)^{(38)}$, in United Kingdom by Beg et 
al. $(2016)^{(31)}$ and in Sweden by Fagerström and Frisman $(2017)^{(41)}$ reported that the main cause of liver cirrhosis for the patients was alcoholic liver disease. The present study result can be justified by that Egypt has the highest $\mathrm{HCV}$ prevalence in the world and the main cause of liver cirrhosis among elderly is $\mathrm{HCV}^{(42)}$. Additionally, alcohol is generally considered to be forbidden in Islam.

Regarding hospital admission in the last year, about two third of the studied female geriatric patients were hospitalized in the last year either one or more times (table 2). The cause may be that all of the studied female geriatric patients suffering from complications such as ascites, haematemsis or melena, jaundice and hepatic encephalopathy (table 2) which need close supervision and treatment. This result agrees with the findings of other studies done in Egypt, Mansoura by Elshamy $(2019)^{(36)}$ and Port Said by Risk (2015) ${ }^{(43)}$ who revealed that more than half of patients were previously hospitalized. Conversely, a study done in Iran by Zandi et al. (2005) ${ }^{(39)}$ reported that more than half of the patients were not previously hospitalized in the last year.

As regard reasons for current hospital admission, about three quarters of the studied female geriatric patients reported the reasons were either ascites and difficult breathing or haematemsis or melena (table 2). This may be due to all of these reasons are complications of liver cirrhosis which need proper management and hospitalization. The present study is in agreement with a study done in Australia by Wigg et al. (2013) ${ }^{(38)}$ and in Egypt, Cairo by Mahmoud et al. (2013) ${ }^{(14)}$ who found that about one quarter of the patients entered the hospital by hematemesis while about one third entered hospital by ascites. Also, study done in USA by Volk et al. (2012) ${ }^{(44)}$ demonstrated that The most common causes among patients with decompensated cirrhosis for hospital readmissions were ascites and hepatic encephalopathy.

Gerontological nurses should be able to offer health information and education to geriatric patients to raise their awareness about liver disease and promote healthy-living strategies. Nursing interventions are important to make a difference in the ability of the patient and family to adapt to chronic disease, manage symptoms, recognize the onset of complications and seek health care early. According to the results of the present study, the proposed hypothesis is approved which is female geriatric patients with liver cirrhosis who receive the proposed nursing interventions exhibit higher self-management behaviors than those who do not receive the proposed interventions.

\section{Conclusion}

From this study it can be concluded that nursing interventions had affected positively the level of knowledge and self-management behaviors of female geriatric patients with liver cirrhosis. Yet, occurrence of complications, readmission to hospital and death rate could not be affected significantly by nursing interventions in study group. The main factors affected significantly self-management behaviors of female geriatric patients were age, educational level and income.

\section{Recommendations}

Based on the findings of this study, the following recommendations are suggested:

- Encouraging the educational campaigns on T.V, internet and all over the whole parts of Egypt to increase the female geriatric patients awareness and knowledge about LC.

- Coordination with different health care settings for application of this program for geriatric patients with compensated LC admitted to out-patient clinics for better results, prevention of complication, decreased hospitalizations and resource utilization.

- Encouragement of geriatric patients with LC to do periodic medical check-up for early detection of complications as hepatocellular carcinoma through announcement on T.V and internet about health services and resources available for these patients.

- Develop an In-service educational program for nurses and health care personnel in the study setting about normal age related changes affecting the liver, complication of LC, available health resources and appropriate interventions for older adults suffering from LC such as diet and follow up. 
Table (1): Distribution of the study and control groups according to their sociodemographic characteristics

\begin{tabular}{|c|c|c|c|c|c|}
\hline \multirow[t]{2}{*}{ Items } & \multicolumn{2}{|c|}{$\begin{array}{c}\text { Study group } \\
(\mathrm{n}=\mathbf{2 5})\end{array}$} & \multicolumn{2}{|c|}{$\begin{array}{c}\text { Control group } \\
(n=25)\end{array}$} & \multirow[t]{2}{*}{ Test of significance. } \\
\hline & No & $\%$ & No & $\%$ & \\
\hline $\begin{array}{l}\text { Age in years: } \\
60- \\
75- \\
\geq 85+\end{array}$ & $\begin{array}{c}23 \\
2 \\
0\end{array}$ & $\begin{array}{c}92.0 \\
8.0 \\
0\end{array}$ & $\begin{array}{c}22 \\
2 \\
1 \\
\end{array}$ & $\begin{array}{l}88.0 \\
8.0 \\
4.0\end{array}$ & $\begin{aligned} \chi^{2} & =1.081 \\
\mathrm{MC} & =1.000\end{aligned}$ \\
\hline Mean \pm SD & \multicolumn{2}{|c|}{$66.84 \pm 4.26$} & \multicolumn{2}{|c|}{$66.1 \pm 6.3$} & $\begin{array}{l}\mathrm{t}=0.473 \\
\mathrm{p}=0.639\end{array}$ \\
\hline $\begin{array}{l}\text { Marital status: } \\
\text { Married } \\
\text { Widow/ Single }\end{array}$ & $\begin{array}{l}14 \\
11\end{array}$ & $\begin{array}{l}56.0 \\
44.0 \\
\end{array}$ & $\begin{array}{l}13 \\
12 \\
\end{array}$ & $\begin{array}{l}52.0 \\
48.0\end{array}$ & $\begin{array}{l}\chi^{2}=1.983 \\
p=1.000\end{array}$ \\
\hline $\begin{array}{l}\text { Level of education: } \\
\text { Illiterate } \\
\text { Read and write } \\
\text { Basic education } \\
\text { Secondaryl university education }\end{array}$ & $\begin{array}{c}14 \\
6 \\
5 \\
0\end{array}$ & $\begin{array}{c}56.0 \\
24.0 \\
20.0 \\
0\end{array}$ & $\begin{array}{c}16 \\
8 \\
0 \\
1\end{array}$ & $\begin{array}{c}64.0 \\
32.0 \\
0 \\
4.0 \\
\end{array}$ & $\begin{array}{c}\chi^{2}=6.244 \\
{ }_{\mathrm{MC}}=0.081\end{array}$ \\
\hline $\begin{array}{l}\text { Residence: } \\
\text { Rural } \\
\text { Urban }\end{array}$ & $\begin{array}{c}18 \\
7\end{array}$ & $\begin{array}{l}72.0 \\
28.0\end{array}$ & $\begin{array}{l}14 \\
11\end{array}$ & $\begin{array}{l}56.0 \\
44.0 \\
\end{array}$ & $\begin{array}{l}\chi^{2}=1.713 \\
p=0.671\end{array}$ \\
\hline $\begin{array}{l}\text { Living arrangement: } \\
\text { Living with family } \backslash \text { relatives } \\
\text { Living alone }\end{array}$ & $\begin{array}{c}24 \\
1\end{array}$ & $\begin{array}{c}96.0 \\
4.0 \\
\end{array}$ & $\begin{array}{c}21 \\
4 \\
\end{array}$ & $\begin{array}{l}84.0 \\
16.0\end{array}$ & $\begin{aligned} \chi^{2} & =2.103 \\
\mathrm{MC}_{\mathrm{p}} & =0.695\end{aligned}$ \\
\hline $\begin{array}{l}\text { Income: } \\
\text { Not enough } \\
\text { Enough }\end{array}$ & $\begin{array}{l}15 \\
10\end{array}$ & $\begin{array}{l}60.0 \\
40.0\end{array}$ & $\begin{array}{l}13 \\
12 \\
\end{array}$ & $\begin{array}{l}52.0 \\
48.0\end{array}$ & $\begin{array}{c}\chi^{2}=0.325 \\
\mathrm{FE}=0.776\end{array}$ \\
\hline $\begin{array}{l}\text { Source of income: } \\
\text { Pension } \\
\text { Family }\end{array}$ & $\begin{array}{c}16 \\
9\end{array}$ & $\begin{array}{l}64.0 \\
36.0\end{array}$ & $\begin{array}{l}13 \\
12\end{array}$ & $\begin{array}{l}52.0 \\
48.0\end{array}$ & $\begin{array}{c}\chi^{2}=0.739 \\
\mathrm{FE}_{\mathrm{p}}=0.390\end{array}$ \\
\hline
\end{tabular}


Table (2): Distribution of the study and control groups according to history of liver cirrhosis, and reasons of current hospital admission

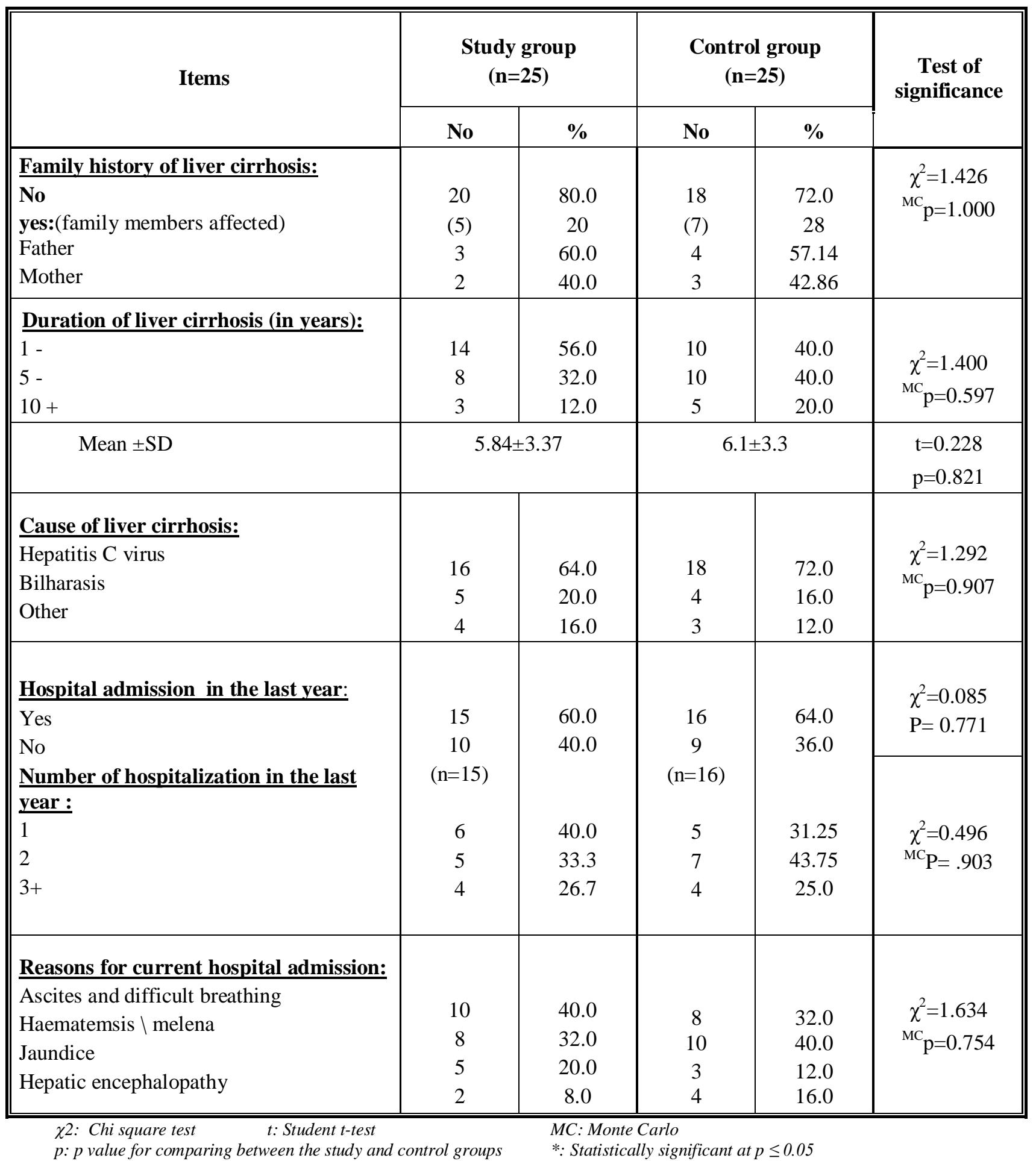


Table (3): Distribution of the study and control groups according to their level of knowledge regarding liver cirrhosis pre and post interventions

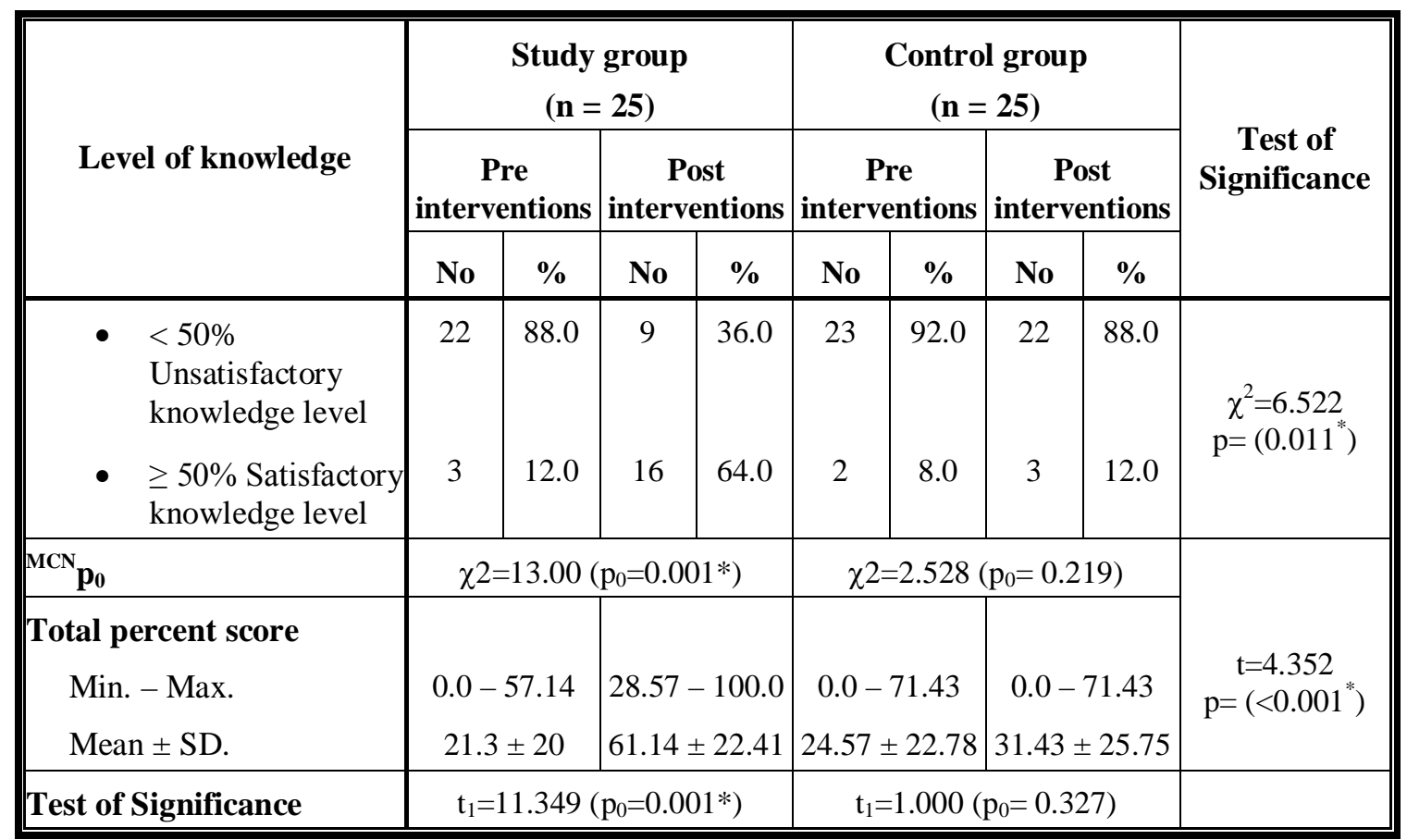

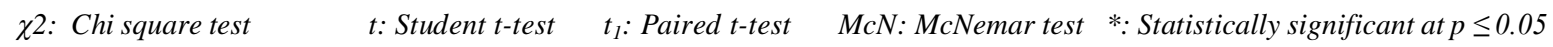
$P: p$ value for comparing between the study and control groups post interventions $p_{0}$ : $p$ value for comparing between pre and post interventions in each group 
Table (4): Comparison of pre/post interventions mean score of self -management behaviors in the study and control groups

\begin{tabular}{|c|c|c|c|c|c|}
\hline \multirow{2}{*}{ Items } & \multicolumn{2}{|c|}{$\begin{array}{l}\text { Study group } \\
\quad(n=25)\end{array}$} & \multicolumn{2}{|c|}{$\begin{array}{c}\text { Control group } \\
(n=25)\end{array}$} & \multirow{2}{*}{$\begin{array}{c}\text { Test of } \\
\text { significance }\end{array}$} \\
\hline & $\begin{array}{c}\text { Pre } \\
\text { interventions }\end{array}$ & $\begin{array}{c}\text { Post } \\
\text { interventions }\end{array}$ & $\begin{array}{c}\text { Pre } \\
\text { interventions }\end{array}$ & $\begin{array}{c}\text { Post } \\
\text { interventions }\end{array}$ & \\
\hline \multicolumn{6}{|l|}{$\begin{array}{l}\text { Dietary management } \\
\text { Total score }\end{array}$} \\
\hline Min. - Max. & $8.0-20.0$ & $9.00-23.00$ & $9.0-17.0$ & $9.00-17.00$ & $\mathrm{t}=4.996$ \\
\hline Mean \pm SD & $11.60 \pm 2.94$ & $17.40 \pm 3.87$ & $11.72 \pm 2.46$ & $12.68 \pm 2.70$ & $\mathrm{p}=\left(0.001^{*}\right)$ \\
\hline Test of significance & \multicolumn{2}{|c|}{$\mathrm{t}_{1}=6.218\left(\mathrm{p}_{0}=0.001^{*}\right)$} & \multicolumn{2}{|c|}{$\mathrm{t}_{1}=1.125\left(\mathrm{p}_{0}=0.272\right)$} & \\
\hline \multicolumn{6}{|l|}{$\begin{array}{l}\text { Daily life management } \\
\text { Total score }\end{array}$} \\
\hline Min. - Max. & $8.0-16.0$ & $10.00-21.00$ & $9.0-20.0$ & $9.00-20.00$ & $\mathrm{t}=1.877$ \\
\hline Mean \pm SD. & $11.80 \pm 1.73$ & $16.04 \pm 3.18$ & $13.32 \pm 3.56$ & $14.24 \pm 3.59$ & $\mathrm{p}=(0.067)$ \\
\hline Test of significance & \multicolumn{2}{|c|}{$\mathrm{t}_{1}=6.072\left(\mathrm{p}_{0}=0.001^{*}\right)$} & \multicolumn{2}{|c|}{$\mathrm{t}_{1}=0.861\left(\mathrm{p}_{0}=0.398\right)$} & \\
\hline \multicolumn{6}{|l|}{$\begin{array}{l}\text { Medication management } \\
\text { Total score }\end{array}$} \\
\hline Min. - Max. & $5.0-13.0$ & $7.00-16.00$ & $5.0-15.0$ & $5.00-15.00$ & $\mathrm{t}=3.934$ \\
\hline Mean \pm SD & $8.76 \pm 1.76$ & $11.76 \pm 2.35$ & $8.72 \pm 2.37$ & $9.08 \pm 2.47$ & $\mathrm{p}=\left(0.001^{*}\right)$ \\
\hline Test of significance & \multicolumn{2}{|c|}{$\mathrm{t}_{1}=5.539\left(\mathrm{p}_{0}=0.001^{*}\right)$} & \multicolumn{2}{|c|}{$\mathrm{t}_{1}=0.565\left(\mathrm{p}_{0}=0.577\right)$} & \\
\hline \multicolumn{6}{|l|}{$\begin{array}{l}\text { Illness- monitoring } \\
\text { management } \\
\text { Total score }\end{array}$} \\
\hline Min. - Max. & $5.0-11.0$ & $5.00-17.00$ & $5.0-10.0$ & $5.00-11.00$ & $\mathrm{t}=4.082$ \\
\hline Mean \pm SD & $6.24 \pm 1.48$ & $10.80 \pm 3.23$ & $7.32 \pm 1.57$ & $7.80 \pm 1.76$ & $\mathrm{p}=\left(0.001^{*}\right)$ \\
\hline Test of significance & \multicolumn{2}{|c|}{$\mathrm{t}_{1}=6.129\left(\mathrm{p}_{0}=0.001^{*}\right)$} & \multicolumn{2}{|c|}{$\mathrm{t}_{1}=0.986\left(\mathrm{p}_{0}=0.334\right)$} & \\
\hline \multicolumn{6}{|l|}{$\begin{array}{l}\text { Overall Self-management } \\
\text { Total score }\end{array}$} \\
\hline Min. - Max. & $29.0-55.0$ & $35.0-69.0$ & $33.0-55.0$ & $34.0-60.0$ & $\mathrm{t}=4.510$ \\
\hline Mean \pm SD & $38.40 \pm 5.17$ & $56.0 \pm 11.17$ & $41.08 \pm 6.08$ & $43.80 \pm 7.63$ & $\mathrm{p}=\left(0.001^{*}\right)$ \\
\hline Test of significance & \multicolumn{2}{|c|}{$\mathrm{t}_{1}=7.012\left(\mathrm{p}_{0}=0.001 *\right)$} & \multicolumn{2}{|c|}{$\mathrm{t}_{1}=1.383\left(\mathrm{p}_{0}=0.179\right)$} & \\
\hline
\end{tabular}

Table (5): Distribution of the study and control groups according to their hospital readmissions, occurrence of complications and number of death post interventions

\begin{tabular}{|c|c|c|c|c|c|}
\hline \multirow[t]{2}{*}{ Items } & \multicolumn{2}{|c|}{$\begin{array}{c}\text { Study Group } \\
(\mathbf{n}=\mathbf{2 5})\end{array}$} & \multicolumn{2}{|c|}{$\begin{array}{l}\text { Control Group } \\
\quad(\mathbf{n}=25)\end{array}$} & \multirow{2}{*}{$\begin{array}{c}\text { Test of } \\
\text { significan }\end{array}$} \\
\hline & No & $\%$ & No & $\%$ & \\
\hline \multicolumn{6}{|l|}{ Hospital readmission in } \\
\hline No & 24 & 96.0 & 21 & 84.0 & \multirow{2}{*}{$\begin{array}{l}\chi^{2}=2.000 \\
\mathrm{FE} p=0.349\end{array}$} \\
\hline yes & 1 & 4.0 & 4 & 16.0 & \\
\hline \multicolumn{6}{|l|}{ Occurrence of new } \\
\hline$\overline{\text { No }}$ & 23 & 92.0 & 20 & 80.0 & \multirow{2}{*}{$\begin{array}{l}\chi 2=2.729 \\
{ }_{\mathrm{MC}}=0.965\end{array}$} \\
\hline Yes & 2 & 8.0 & 5 & 20.0 & \\
\hline \multicolumn{6}{|l|}{ No of death: } \\
\hline No & 25 & 100.0 & 25 & 100.0 & \multirow[t]{2}{*}{-} \\
\hline Yes & 0 & 100.0 & 0 & 0.0 & \\
\hline
\end{tabular}




\section{References}

1. Suva M. A Brief Review on Liver Cirrhosis: Epidemiology, Etiology, Pathophysiology, Symptoms, Diagnosis and Its Management. Inventi Rapid: Molecular Pharmacology 2014; (2):1-5.

2. Nusrat $\mathrm{S}$, Khan M, Fazili J \& Madhoun M. Cirrhosis and its complications: evidence based treatment. World Journal of Gastroenterology 2014; 20(18): 5442.

3. Carvalho J, Portugal F, Flor L, Campos M \& Schramm J. Method for estimating the prevalence of chronic hepatitis $\mathrm{B}$ and $\mathrm{C}$ and cirrhosis of the liver in Brazil. Epidemiologia e Serviços de Saúde 2014; 23:691-700.

4. Patil M, Rathod U \& Majethia N. Clinical pathological correlation in 118 autopsy cases of cirrhosis of liver. Indian Journal of Basic and Applied Medical Research 2016; 5(2):667-82.

5. Tajiri K \& Shimizu Y. Liver physiology and liver diseases in the elderly. World journal of gastroenterology: WJG 2013; 19(46): 845967.

6. Rezaei N, Asadi-Lari M, Sheidaei, A, Khademi S, Gohari, K, Delavari F \& FarzadFar F. Liver cirrhosis mortality at national and provincial levels in Iran between 1990 and 2015: A meta regression analysis. Public Library of Science 2019; 14(1): e0198449.

7. World Life expectancy. Liver diseases in Egypt. 2017. Available at https://www.worldlifeexpectancy.com/egyptliver-disease.

8. World Health Organization (WHO), last update, Mortality Databases. 2012.

9. Records of Damanhur National Medical Institute at El-Behaira Governorate. 2017.

10. Kamimura K, Sakamaki A, Kamimura H, Setsu T, Yokoo T, Takamura M \& Terai S. Considerations of elderly factors to manage the complication of liver cirrhosis in elderly patients. World journal of gastroenterology 2019; 25(15): 1817.

11. Khan MS, Roberts MS. Challenges and innovations of drug delivery in older age. Advanced Drug Delivery Reviews 2018; 135: 3-38.

12. Kim H, Kisseleva $\mathrm{T} \&$ Brenner D. Aging and liver disease. Current opinion in gastroenterology 2015; 31(3): 184.

13. Benedict $M \&$ Zhang $X$. Non-alcoholic fatty liver disease: An expanded review. World journal of hepatology 2017; 9(16): 715 .

14. Mahmoud F, Ebeid N \& Abd ElAziz S. The impact of self-care instructional program on quality of life of patients with liver cirrhosis at El Kasr EL Ainy Cairo University
Hospital. Nature and Science 2013; 11(6): 95-105.

15. Wu L, Wu M, Lien G, Chen F \& Tsai J. Fatigue and physical activity levels in patients with liver cirrhosis. Journal of clinical nursing 2012; $21(1-2)$ : 129-38.

16. Hansen L, Leo MC, Chang MF, Zaman A, Naugler W\& Schwartz J. Symptom distress in patients with end-stage liver disease toward the end of life. Gastroenterology Nursing 2015; 38(3): 201- 10.

17. Pinter M, Trauner M, Peck-Radosavljevic M $\&$ Sieghart W. Cancer and liver cirrhosis: implications on prognosis and management. The European Society for Medical Oncology's online-only, peerreviewed open access journal 2016;1(2): e000042.

18. Goldsworthy A, Fateen W, Thygesen H, Aldersley M, Rowe I \& Jones R. Patient understanding of liver cirrhosis and improvement using multimedia education. Frontline gastroenterology 2017; 8(3): 214-9.

19. Volk M, Fisher N, \& Fontana R. Patient knowledge about disease self-management in cirrhosis. The American journal of gastroenterology 2013; 108(3): 302-5

20. Dong N, Chen W, Bao M, Lu Y, Qian Y \& $\mathrm{Lu} \mathrm{H}$. Self-Management Behaviors Among Patients With Liver Cirrhosis in Shanghai, China: A Cross-Sectional Study. Clinical nursing research 2018; 1054773818777914:1-25.

21. Richard A \& Shea K. (2011). Delineation of self-care and associated concepts. Journal of Nursing Scholarship 2011; 43: 255-64.

22. Mansouri P, Ghadami M, Najafi S \&Yektatalab Sh. The Effects of SelfManagement Training on Self-Efficacy of Cirrhotic patients Referring to Transplantation Center of Nemaze Hospital: A Randomized Controlled Trial. International Journal of Community Based Nursing and Midwifery 2017; 5 (3): 256-63.

23. Gimenes F, Motta A, Silva P, Gobbo A, Atila E \& Carvalho E. Identifying nursing interventions associated with the accuracy used nursing diagnoses for patients with liver cirrhosis. Revista Latino-Americana de Enfermagem 2017; 25.

24. Rehaim J \& Mohamed I. Knowledge of Patient with Liver Cirrhosis Regarding Ascites Self-Management: Instructions Nursing Guideline. IOSR Journal of Nursing and Health Science 2017; 6 (4): 88-95.

25. Elokl M. Prevalence of Alzhemier Dementia and other Causes of Dementia in Egyptian 
elderly. Unpublised Master Thesis, Faculty of medicine. Ain Shamas University, 2002.

26. Wang Q, Wang Y, Gao J, Han J \& Li Y. Development of a self-management behaviour scale for liver cirrhosis. International Journal of Nursing Sciences 2015; 2(1): 73-9.

27. Fabrellas N, Carol M, Palacio E, Aban M, Lanzillotti T, Nicolao $G$ \& Gossard A. Nursing Care of Patients With Cirrhosis: The Liver Hope Nursing Project. Hepatology 2020; 71(3): 1106-16.

28. Alavinejad P, Hajiani E, Danyaee B \& Morvaridi M. The effect of nutritional education and continuous monitoring on clinical symptoms, knowledge, and quality of life in patients with cirrhosis. Gastroenterology and hepatology from bed to bench 2019; 12(1): 17-24.

29. Zhang X, Xi W, Liu L, \& Wang L. Improvement in Quality of Life and Activities of Daily Living in Patients with Liver Cirrhosis with the Use of Health Education and Patient Health Empowerment. Medical science monitor: international medical journal of experimental and clinical research 2019; 25: 4602-8.

30. Bae O \& Suh R. Effect of structured information provided on knowledge and selfcare behavior of liver cirrhosis patients. Korean Journal of Adult Nursing 2001; 13(3): 476-85.

31. 31.Beg S, Curtis S, \& Shariff M. Patient education and its effect on self-management in cirrhosis: a pilot study. European Journal of Gastroenterology \& Hepatology 2016; 28(5): 582.

32. Mohamed S \& Mostafa H. The effects of educational intervention on self-care behavior and expected clinical outcome in patient undergoing liver transplantation. Journal of Nursing Education and Practice 2018; 8(9): 102-12.

33. Ko D, Bratzke L, Muehrer R \& Brown R. Self-management in liver transplantation. Applied Nursing Research 2019; 45: 30-8.

34. Ban L, Yu S, Hua X, Wang W, Zou Y, Zhao $\mathrm{Y} \&$ Zhao Q. Contrast analysis of nutritional status between patients of alcoholic cirrhosis and viral cirrhosis. Parenteral \& Enteral Nutrition 2017; 24: 105-8.

35. Polis S, Zang L, Mainali B, Pons R, Pavendranathan G, Zekry A \& Fernandez R. (2016). Factors associated with medication adherence in patients living with cirrhosis. Journal of clinical nursing 2016; 25(1-2): 204-12.
36. Elshamy K, Mohammed $\mathrm{H}$ and Mohammed M. Impact of Implementing Self-care Protocol on Improving Quality of Life of Patients with Liver Cirrhosis. Natural Sciences 2019; 17(8):1-11.

37. Kadokawa Y, Katayama K, Takahashi K, Fukushima N, Tanaka S, Taniguchi Y, et al. The Effectiveness of a Liver Disease Education Class for Providing Information to Patients and Their Families. Journal of Clinical Medicine and Research 2017; 9: 207.

38. Wigg J, McCormick R, Wundke R \& Woodman J. Efficacy of a chronic disease management model for patients with chronic liver failure. Clinical Gastroenterology and Hepatology 2013; 11(7): 850-8.

39. Zandi M, Adib-Hajbagheri M, Memarian R, Nejhad A, \& Alavian S. Effects of a self-care program on quality of life of cirrhotic patients referring to Tehran Hepatitis Center. Health and quality of life outcomes 2005; 3(1): 35 .

40. Saleh M, Mustafa H, Eid Kh, Soliman M \& Sultan H. Assessment of nutritional status of patients with chronic liver diseases admitted to gastroenterology department at Al-Azhar University Hospital, Assiut. Al-Azhar Assiut Medical Journal 2014; 12(3):89-110.

41. Fagerström C, Frisman GH. Living with liver cirrhosis: a vulnerable life. Gastroenterology Nursing journal 2017; 40(1): 38-46.

42. Kandeel A, Genedy M, El Refai S, Funk A, Fontanet A, \& Talaat M. The prevalence of hepatitis C virus infection in Egypt 2015: implications for future policy on prevention and treatment. Liver International 2017; 37(1): 45-53.

43. Rizk Sh. Impact of Educational Program on Quality of Life in Hepatitis C infected patients Treated by Interferon and Ribavirin, unpublished thesis for Partial Fulfillment of Doctoral Degree in Medical Surgical Nursing, Faculty of Nursing, Port Said University. 2015.

44. Volk M, Tocco R, Bazick J, Rakoski M \& Lok A. Hospital re-admissions among patients with decompensated cirrhosis. The American journal of gastroenterology 2012; 107(2): 247. 